\title{
HERBICIDE STUDIES IN LANDSCAPE PLANTINGS
}

\author{
MAY 1972 - NUMBER 5
}

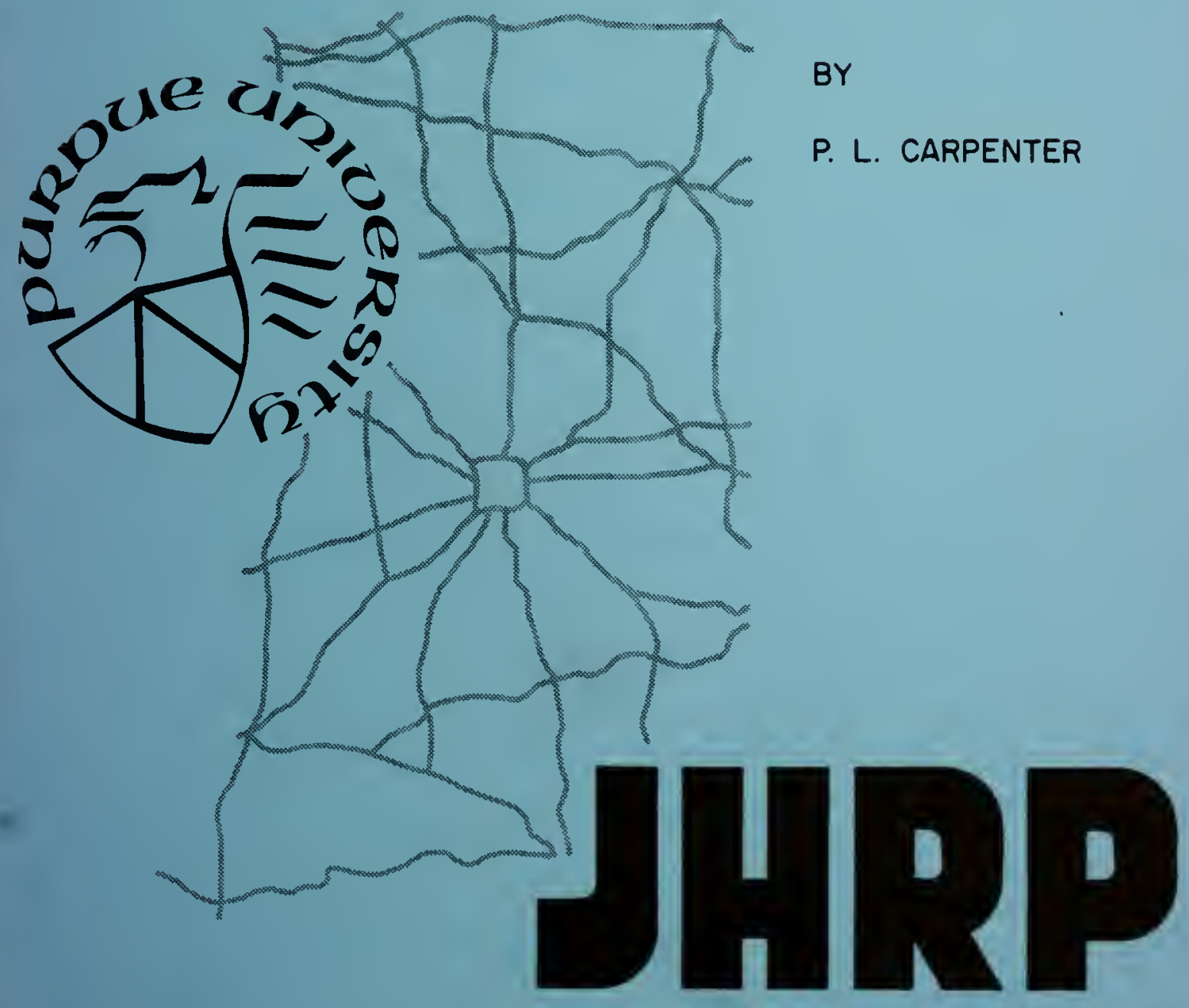

JOINT HIGHWAY RESEARCH PROJECT PURDUE UNIVERSITY AND 

HERBICIDE STUDIES IN LANDSCAPE PLANTINGS

TO: J. F. McLaughlin, Director Joint Highway Research Project

FROM: H. L. Michael, Associate Director Joint Highway Research Project
May 16, 1972

Project: $\quad C-36-48 C$

File: $9-5-3$

The attached Interim Report titled "Herbicide Studies in Landscape Plantings" is submitted on Part II of the HPR Part II Research Study "Research in Roadside Development and Maintenance". Professor P. L. Carpenter, principal investigator on this portion, has authored this report.

The report includes a number of recommendations for consideration by highway personnel in managing the roadside through use of herbicides in landscape plantings.

The Report is presented for acceptance as partial fulfillment of the objectives of the referenced research study and will also be forwarded for review, comment and similar acceptance to the ISHC and FHWA.

$H L M: m s$

Respectfully submitted,
CC: W. L. Dolch
R. L. Eskew
W. H. Goetz
W. L. Grecco
M. J. Gutzwiller
G. K. Hallock
M. E. Harr
R. H. Harrell
M. I. Hayes
R. D. Miles
J. W. Miller
C. F. Scholer

M. B. scott

J. A. Spooner

N. W. Steinkamp

H. R. J. Walsh

K. B. Woods

E. J. Yoder 
Digitized by the Internet Archive in 2011 with funding from

LYRASIS members and Sloan Foundation; Indiana Department of Transportation 


$$
\begin{aligned}
& \text { Interim Report } \\
& \text { HERBICIDE STUDIES IN LANDSCAPE PLANTINGS } \\
& \text { by } \\
& \text { P. L. Carpenter } \\
& \text { Department of Horticulture } \\
& \text { Purdue University } \\
& \text { Joint Highway Research Project } \\
& \text { Project No.: } C-36-48 C \\
& \text { File No.: } 9-5-3
\end{aligned}
$$

The opinions, findings and conclusions expressed in this publication are those of the authors and not necessarily those of the Federal Highway Administration.

Purdue University

Lafayette, Indiana

May 16, 1972 
TABLE OF CONTENTS

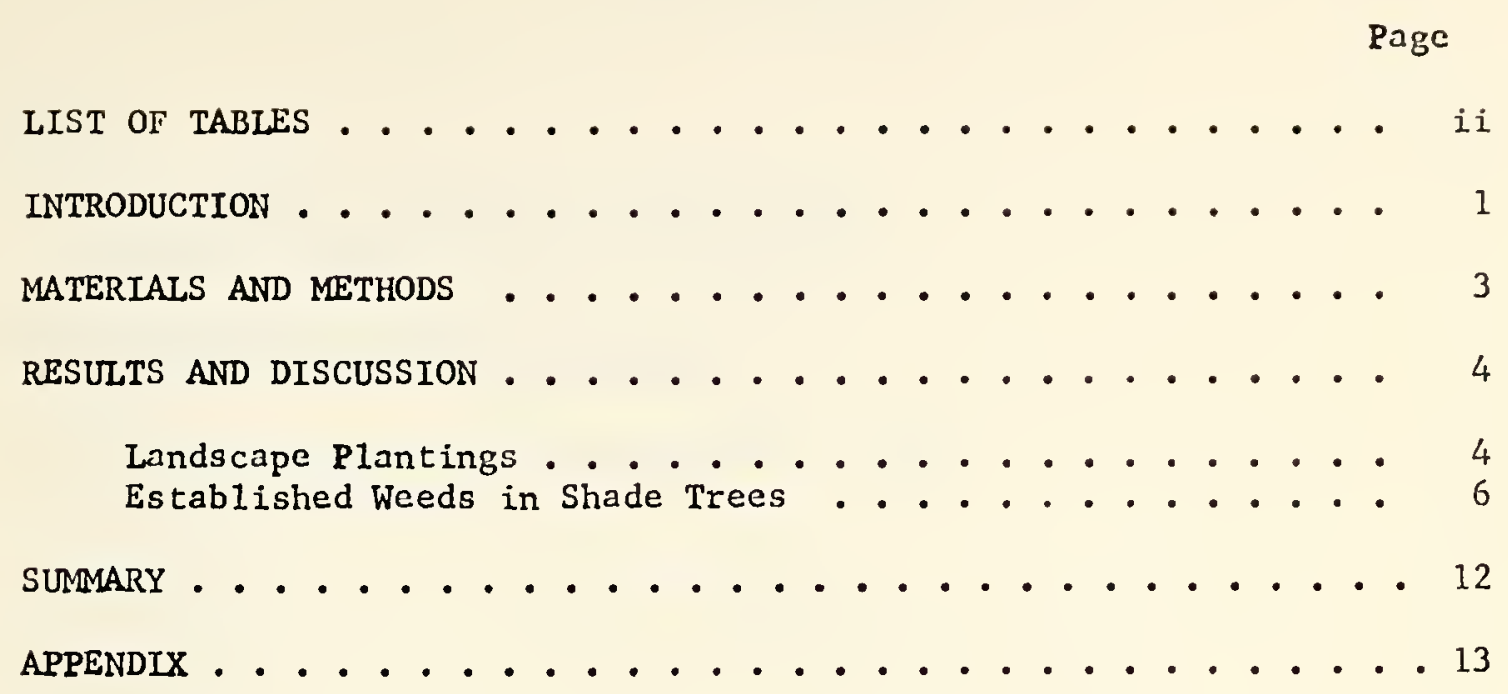


ii

LIST OF TABLES

Table

Page

1. Comparison of Weed Control With Three

Herbicides Applied With Three Carriers . . . . . . . . . 5

2. Control of Field Bindweed With Three

Herbicides Mixed in Bark Mulch . . . . . . . . . . 7

3. Control Bindweed Using Dichlobenil in the

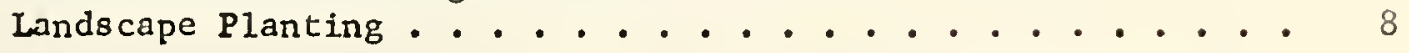

4. Quack Grass in the Landscape Planting . . . . . . . . . 10

5. Control Established Weeds in 2" to $3^{\prime \prime}$ Silver Maples . . . . 11 


\section{HERBICIDE STUDIES IN LANDSCAPE PLANTINGS}

\section{INTRODUCTION}

The landscape planting poses several difficult problems when considering the use of herbicides. First, the plantings to be covered are often irregular shaped and accurate determination of the area involved is difficult. Also, the areas are often times small and accurate application of small amounts of herbicides is difficult, if not impossible, with present day equipment.

Due to the usual close proximity of turf to the landscape planting, the problem of herbicide usage is further compounded. Many herbicides that can be used on woody ornamentals will damage turf. Not only is it important to keep the herbicide off of the surrounding turf during application, but also, there must be no lateral movement of herbicide from the landscape bed to the turf area after application is made.

Finally, many plantings contain such a wide range of plant material it is often times difficult to find an effective herbicide that is labeled for all the plants.

The physical problems of accurate application of herbicides to landscape reported plantings have been partially solved in the results of pervious research reported in JHRP progress reports by Lanphear and Spangler. Those studies have shown that certain herbicides can be mixed on a volume basis with mulches. The mulchherbicide mixture is then applied on a depth basis to the landscape 
bed. Weed control using dichlobenil as the herbicide was very good, and lateral movement of the herbicide was reduced. The only way the herbicide can move from the bed is by the actual movement of the bark mulches onto the turf area. The use of bark mulches plus dichlobenil is recommended for highway landscape plantings provided the plants invloved are listed on the dichlobenil label.

The use of bark mulch is not always feasible either from a use point of view or for financial reasons. For these reasons other carriers of herbicides for landscape plantings as well as spraying the herbicides on a water-degradable, cellulose blanket which was then applied to the landscape bed. The blanket was covered with a plastic net which broke down by the end of the summer. These methods were compared to the bark mulch method developed by Lanphear.

Also, often weeds become established in highway plantings before pre-emergence herbicide can be used by itself or in mulches. It may be desirable to knock down the existing weed growth with a contact herbicide. The feasibility of using a pre-emergence herbicide with the contact herbicide to reduce the amount of weed regrowth was investigated.

This progress report supplements work reported in previous progress reports filed by Landphear and Spangler. 
MATERIALS AND METHODS

The test plots were set up in the Fort Wayne area in various landscape situations. Applications of treatments were made on April 23 and April 30. The plots were cleaned before treatment application. The blankets were sprayed in Lafayette and wrapped in plastic to prevent volatilization of the herbicides. The blankets were precut to the $4^{\prime} \times 5^{\prime}$ plot size, and were fastened down in the landscape planting with $6^{\prime \prime}$ to $8^{\prime \prime}$ wire staples. The herbicides were mixed in the bark and the sand treatments in Lafayette, bagged in burlap bags, and transported to Fort Wayne for application. The sand was applied $\frac{1}{2} "$ in depth and the bark mulch was $2^{\prime \prime}$ deep. The three herbicides used were dichlobenil $4 \mathrm{lb} / \mathrm{A}$, trifluralin $2 \mathrm{lb} / \mathrm{A}$, and simazine $1 \mathrm{lb} / \mathrm{A}$ plus diphenamid $4 \mathrm{lb} / \mathrm{A}$. All treatments were replicated three times at two different sites. Weed counts were taken at three times during the summer.

On the 23 rd of July, five herbicide combinations were applied to a block of silver maple with established, actively growing weeds. In this experiment a contact herbicide was needed to kill the weeds already established. Prc-cmergence herbicides were used in combination with the contact killers to prevent the development of new weed growth. The herbicides wore applied with a knapsack sprayer. Paraquat was one of the contact killers used and a second application on August 8 was required. 


\section{RESULTS AND DISCUSSION}

\section{Landscape plantings}

It can be seen in Table 1 that the best weed control was obtained using the bark mulch with dichlobenil (Treatment 11). Dichlobenil mixed in sand provided nearly as satisfactory control (Treatment 3). The blanket treated with dichlobenil also provided satisfactory control of weeds (Treatment 7). At one site it was extremely windy on the day of application and some of the dichlobenil may have volatilized before the blankets could be properly applied. A11 other herbicides except the simazine-diphenamid combination applied to the blanket did not give satisfactory weed control. Table 1 presents the total weed counts for all six treatments.

From a commercial point of view the use of sand as a carrier is not practical due to the weight factor. Also, trying to apply sand to a depth $\frac{1}{2} "$ is difficult due to the uneven soil surface. The blanket when broken down by water is unattractive and the plastic net lasts too long.

The bark mulch alone greatly reduced annul weed growth. However, if perennial weeds were a problem the bark mulch did not prevent their development of growth. In a landscape planting 2 inch bark mulch plus herbicide treatments were applied on May 21. The techniques of mixing the herbicides in the bark mulch were the same as described in the previous experiment. Bindweed counts were taken on July 19 and September 17 . The number of bindweed 
Table 1

Comparison of Weed Control With Three Herbicides Applied With Three Carriers

\begin{tabular}{|c|c|c|c|c|c|c|c|}
\hline \multirow{2}{*}{\multicolumn{2}{|c|}{ Treatments }} & \multicolumn{3}{|c|}{ Broadleafs on } & \multicolumn{2}{|c|}{ Grasses } & \multirow{2}{*}{$\begin{array}{c}\text { on } \\
\text { Sept } \\
17 \\
\end{array}$} \\
\hline & & June & July & Sept & June & July & \\
\hline 2. & Contro1 & 889 & 273 & 259 & 106 & 57 & 20 \\
\hline 2. & Sand $\frac{1}{2} "$ & 634 & 140 & 203 & 134 & 38 & 14 \\
\hline 3. & Sand + dichlobenil 4非/A & 2 & 6 & 34 & 0 & 0 & 0 \\
\hline 4. & Sand + trifluralin 2非/A & 431 & 84 & 72 & 38 & 14 & 4 \\
\hline 5. & $\begin{array}{l}\text { Sand + samazine 1非/A + } \\
\text { diphenamid 4非/A }\end{array}$ & 153 & 41 & 67 & 14 & 12 & 10 \\
\hline 6. & Blanket & 254 & 340 & 292 & 32 & 75 & 29 \\
\hline 7. & Blanket + dichlobenil 4非/A & 17 & 49 & 67 & 14 & 12 & 14 \\
\hline 8. & Blanket + trifluralin 2非/A & 42 & 128 & 166 & 0 & 14 & 19 \\
\hline 9. & $\begin{array}{l}\text { Blanket }+ \text { simazine } 1 \text { 非 } / \mathrm{A}+ \\
\text { diphenamid } 4 \text { 非/A }\end{array}$ & 0 & 19 & 98 & 7 & 21 & 13 \\
\hline 10 . & Bark Mulch $2^{\prime \prime}$ & 33 & 14 & 12 & 17 & 20 & 11 \\
\hline 11. & Bark + dichlobenil 4非/A & 0 & 0 & 1 & 0 & 0 & 0 \\
\hline 12. & Bark + trifluralin 2非/A & 32 & 39 & 25 & 1 & 1 & 1 \\
\hline 13. & $\begin{array}{l}\text { Bark + simazine } 1 \text { 非/A + } \\
\text { diphenamid } 4 \text { 非/A }\end{array}$ & 15 & 19 & 16 & 1 & 8 & 2 \\
\hline
\end{tabular}


present is reported in Table 2 .

It is evident that only dichlobenil is effective in controlling bindweed in landscape plantings for an entire season. The bark mulch alone and the other herbicides used with the bark mulch did not provide lasting bindweed control.

A fall application and a spring application of dichlobenil mixed in bark mulch were applied to an area heavily infested with established bindweed. The same techniques previously described were used for weed counts and application depths. The rate of dichlobenil was increased to $8 \mathrm{lb} / \mathrm{A}$. The bindweed was counted on June 11 and the results are given in Table 3 .

The results indicate that a late fall application of bark mulch plus dichlobenil 8 1b/A. will satisfactorily control bindweed. Dichlobenil $8 \mathrm{lb} / \mathrm{A}$. alone reduces bindweed; however, the mulch alonc does not.

Quack grass in the landscape situation is another problem. The treatments 1 isted in Table 4 were applied in the same manner as those 1isted in Table 1. The cellulose blanket was not used at this site. The amount of quack grass present on June 19 and July 30 is given in Table 4. Though most herbicides reduce quack grass only dichlobenil was effective in providing lasting control. It should be noted that complete control was not obtained with any material.

\section{Established Weeds In Shade Trees}

After application of treatments at the end of July weed counts were made on October 10. In Table 5 it can be seen that three treatments gave good weed control. These were Paraquat $\frac{1}{2} 1 \mathrm{~b} / \mathrm{A}$. plus 
Table 2

Control of Field Bindweed With

Three Herbicides Mixed in Bark Mulch

\begin{tabular}{lcc}
\hline \multicolumn{1}{c}{ Treatment } & \multicolumn{2}{c}{ Bindweed on } \\
1. Control & 30 & Sune 19 \\
2. Bark Mulch--2" & 27 & 30 \\
3. Bark + dichlobeni1 4非/A & 0 & 46 \\
4. Bark + trifluralin 2非/A & 1 & 36 \\
5. Bark + simazine 1非/A & 1 & 36 \\
6. Bark + diphenamid 6非/A & 12 & 33 \\
\hline
\end{tabular}


Table 3

Control Bindweed Using Dichlobenil

in the Landscape Planting

\begin{tabular}{lcc}
\hline \multicolumn{1}{c}{ Treatment } & \multicolumn{2}{c}{ Applied on } \\
\hline Control & 212 & Apri1 16 \\
dichlobeni1 8\#/A & 11 & 29 \\
Bark Mulch 2" + dichlobenil 8\#/A & 3 & 0 \\
Bark Mulch 2" & 220 & 202 \\
\hline
\end{tabular}

Totals from three $2^{\prime} \times 8^{\prime}$ plots per treatment. 
simazine 3 1b/A, Paraquat $\frac{2}{2}$ 1b/A. plus Simazine 1 1b/A and diphenamid $4 \mathrm{lb} / \mathrm{A}$, and Amizine $6 \mathrm{lb} / \mathrm{A}$. Paraquat is a contact herbicide that kills green portions of the plant. It is not selective and must be kept off the green portions of the plants that are not to be killed. It is not translocated in the plant. Amazime is a combination of amitrole and simazine. Amitrole is a contact herbicide that is translocated in the plant. Therefore, Amizine can kill the entire plant even though it only comes in contact with a portion of the plant. It is also non-selective. The weed counts are given in Table 5.

It is apparent that Paraquat will "knock down" weeds to soil level and simazine $31 \mathrm{~b} / \mathrm{A}$ or simazine $1 \mathrm{lb} / \mathrm{A}$ plus diphenamid $4 \mathrm{lb} / \mathrm{A}$ will prevent the return of weed growth. These treatments show promise for controlling cstablished weeds around shade trees on the roadside. Paraquat apparently will be safer to the plant to use than Amizine since it is not translocated. Paraquat alone is only a chemical hoe and weed growth soon develops anew after its use. It cannot be used on any plants such as shrubs where it will be in contact with the green portion of the plants. 


\section{Table 4}

Quack Grass in the Landscape Planting

\begin{tabular}{|c|c|c|c|}
\hline \multicolumn{2}{|r|}{ Treatment } & \multicolumn{2}{|c|}{ Grass on } \\
\hline 1. & Control & 41 & 125 \\
\hline 2. & Sand $\frac{11 \prime}{2}$ & 56 & 63 \\
\hline 3. & Sand + dichlobenil 4非/A & 1 & 4 \\
\hline & Sand + trifluralin 2非/A & 17 & 28 \\
\hline 5. & Sand + Simazine 1非/A + Diphenamid 4非/A & 17 & 47 \\
\hline 6. & Bark Mulch 2" & 31 & 46 \\
\hline 7. & Bark + dichlobenil 4非/A & 2 & 15 \\
\hline 8 . & Bark + triflurahin 2非/A & 34 & 87 \\
\hline 9. & Bark + Simazine 1非/A + Diphenamid 4非/A & 54 & 46 \\
\hline
\end{tabular}


Table 5

Control Established Weeds in

$2^{\prime \prime}$ to $3^{\prime \prime}$ Silver Maples

\begin{tabular}{|c|c|c|}
\hline Treatments & $\begin{array}{l}\text { Weeds on } 0 \\
\text { Broadleaf }\end{array}$ & $\begin{array}{r}\text { ct. } 10 \\
\text { Grass } \\
\end{array}$ \\
\hline 1. Control & 211 & 52 \\
\hline 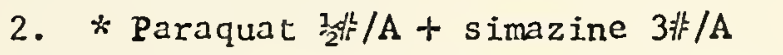 & 9 & 30 \\
\hline 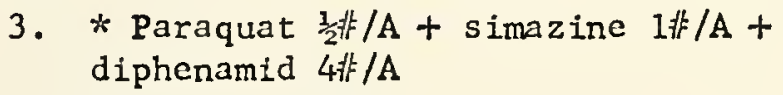 & 20 & 28 \\
\hline 4. * Paraquat $\frac{3}{2}$ 非/A & 89 & 230 \\
\hline 5. Diphenamid--dinitro 2 gallon/A & 169 & 140 \\
\hline 6. Amizine 6非/A & 9 & 21 \\
\hline
\end{tabular}

* A second application of Paraquat was made on August 8 . Rate was $\frac{1}{2}$ 非/A 


\section{SUMMARY}

The problems unique with controlling weeds in highway landscape plantings have been partially solved. The following recommendations can be made for consideration by highway management personnel.

1. A bark mulch with dichlobenil $4 \mathrm{lb} / \mathrm{A}$ incorporated will provide satisfactory control of weeds in landscape plantings.

2. Use this mulch-herbicide combination only on those plants Iisted on the dichlobenil label.

3. Further work needs to be done on other methods of applying herbicides to landscape plantings. Sand and the cellulose blanket used as carriers are not satisfactory.

4. Paraquat can be used to reduce or "knock down" established weed growth in shade trees and areas where the green portions of the crop plant will not be in contact with the herbicide.

5. Combinations of herbicides using Paraquat and pre-emergence materials will provide one season weed control.

6. Paraquat is hazardous to use and safety precautions should be followed. (See appendix) 
APPENDIX

\section{TOXICITY OF PARAQUAT}

Due to some recent fatal poisonings from Paraquat, it is suggested that the following precautions be taken when using the material:

1. Do not store in any unlabeled container; store only in original container.

2. Store out of reach of children and away from foods.

3. Avoid any skin or eye contact.

4. Wear protective clothing when handling and applying Paraquat, including gloves, face shield or other eye protectors, and a protective device to prevent inhaling of fumes and drift.

5. Avoid exposures to drifts and fumes.

6. Train personnel before permitting their use of Paraquat.

7. Do not smoke, drink, or eat in areas where Paraquat is being used.

8. Wash protective clothing after use.

9. Wash thoroughiy after use.

Several fatalities have resulted when Paraquat has been consumed accidently. Permanent damage to eyes and lungs has resulted when not used properly. The damage is permanent. There are no known antidotes so be very careful. 

